\title{
Clinical Study to Evaluate Role of Autogeneous Graft in ACL Reconstruction using Two Different Techniques
}

\author{
Dr Sahil Saini ${ }^{1}$, Dr Manu Soni ${ }^{2}$ \\ ${ }^{1,2,3}$ Department of Orthopaedics ; M. M Institute of Medical Sciences \& Research; (MULLANA); Ambala; Haryana
}

\begin{abstract}
Study Design: Clinical Study to evaluate the role of autogeneous graft in ACL reconstruction. Summary of Background data: ACL reconstruction can be done by either bone patellar tendon or hamstring tendon as graft by either transtibilal or anteromedial portal technique. Methods: Total of 30 patients with partial to complete ACL tear were arthroscopically reconstructed using patellar or hamstring tendon graft and evaluation of results was done according to Lysholm score. Results: Postoperatively patients in both group showed Lysholm score of more than 90 with significant clinical improvement.
\end{abstract}

Keywords: (ACL): Anterior cruciate ligament, (BPT) : Bone Patellar Tendon

\section{Introduction}

ACL is an intra-articular, extrasynovial structure present in central complex of knee joint with function to control and limit motion and to maintain both static and dynamic equilibrium which is commonly injured in athletic activities or without a fall or direct contact where deceleration along with valgus external rotation or hyperextension force comes into play.

Choice of graft and its fixation plays a key role in ACL reconstruction which can be either BPT tendon or hamstring tendon grafts which are most frequently used autografts today $^{1}$. Currently two fixation methods used by surgeons are transtibial and the antero-medial portal. Ideal graft would be one that provides as much strength as native ACL allows for secure fixation has minimal harvest site morbidity, enables unrestricted rehabilitation and restores normal knee biomechanics. Advantage of hamstring over patellar tendon are reduced donor site morbidity with fewer kneeling problems in long term follow up ${ }^{2}$.

The study is done to access functional outcome of the knee following arthroscopically ACL reconstruction using autogeneous graft.

\section{Materials \& Methods}

We selected 30 patients with partial to complete ACL tear in whom arthroscopic reconstruction was done using BPT and hamstring tendon autograft. Patients with multiple ligament injury, elderly patients with preexisting osteoarthritis and those with fractures around knee were excluded from the study.

Preoperative evaluation was done through history and physical examination with clinical tests like Lachman's test, Ant Drawer test \& Lateral Pivot Shift test. Preoperative routine Xrays \& MRI was done to assess the grade of tear.
Arthroscopy was performed under Regional anaesthesia under strict aseptic conditions in supine position.

Postoperatively antibiotics were given for $24 \mathrm{hrs}$ and limb was elevated to minimise postop pain and swelling. Wound inspection was done every alternate day and sutures were removed on $14^{\text {th }}$ postoperative day. Patients were followed up at 3 wks , 6 wks , 3 months, 6 months, 1 year and results evaluated using Lysholm Knee scoring scale.

\section{Figures \& Tables}

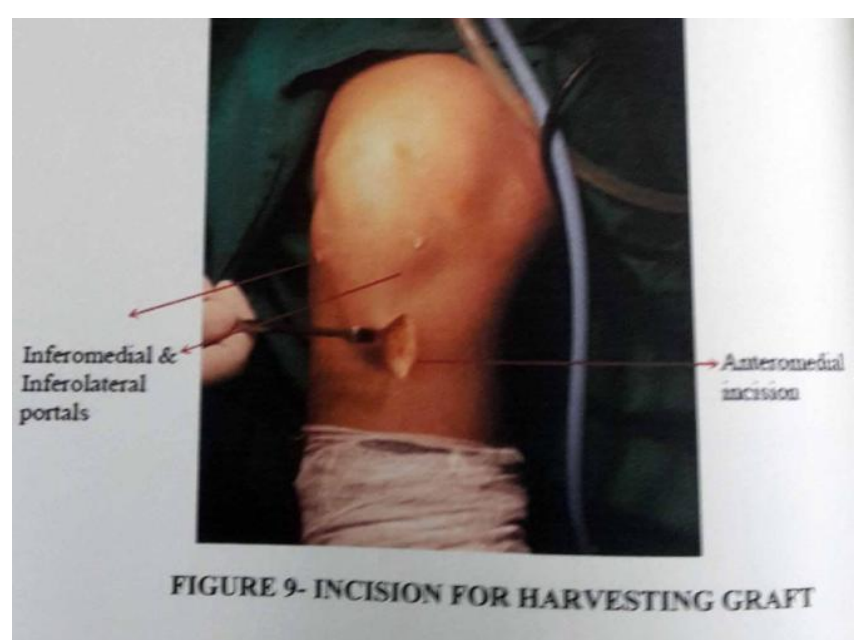

Figure 1: Showing Incision Sites 


\section{International Journal of Science and Research (IJSR)}

ISSN (Online): 2319-7064

Index Copernicus Value (2013): 6.14 $\mid$ Impact Factor (2014): 5.611
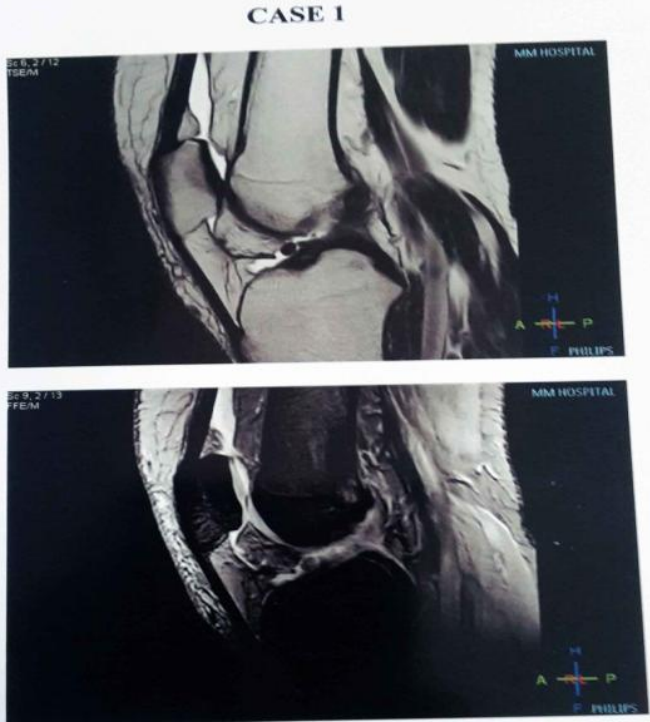

PREOPERATIVE MRI SHOWING ACL TEAR

Figure 2: Showing ACL TEAR

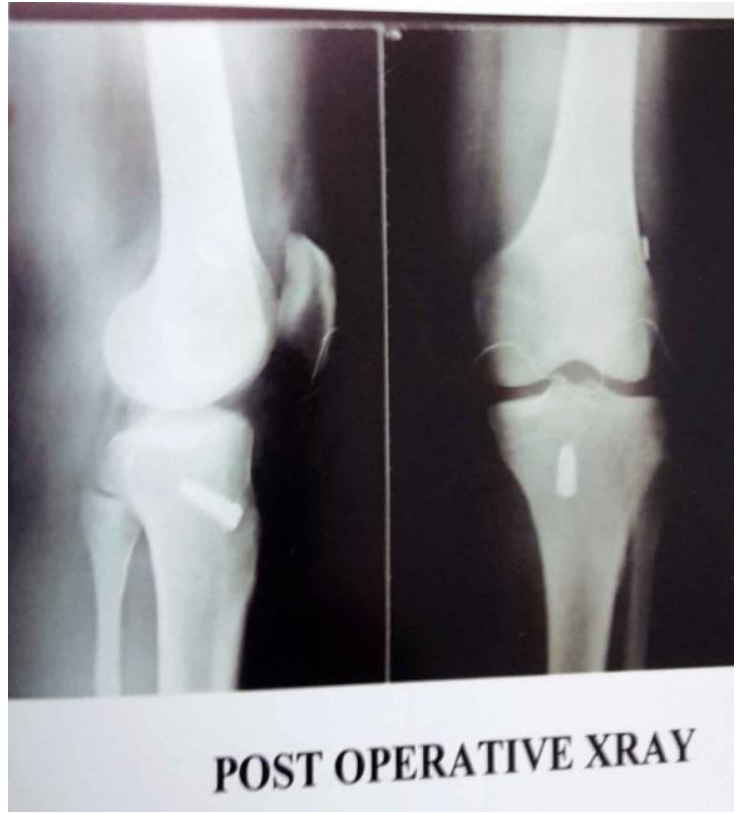

Figure 3: Post Operative XRay
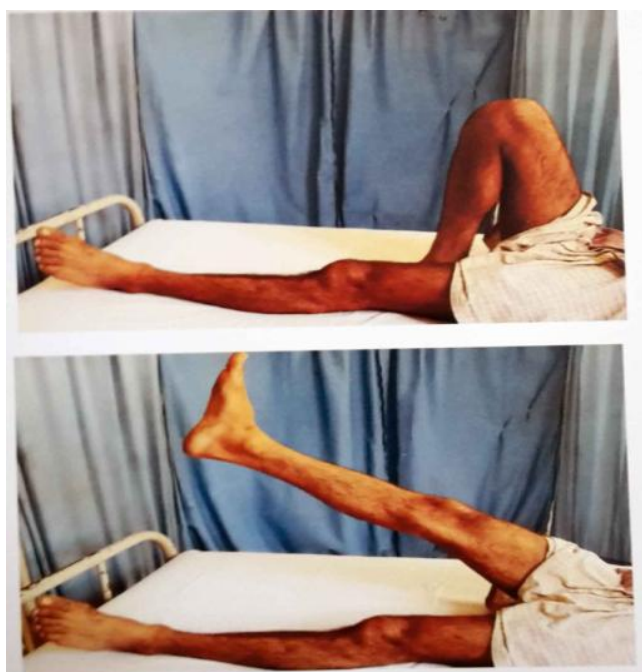

LNICAL PHOTOGRAPHS SHOWING POSTOPERATIVE RANGE OF MOTION

Figure 4: Showing Post OP Range of Motion

Table 1: Graft used

\begin{tabular}{|c|c|c|}
\hline Graft used & No of patients & percent \\
\hline Hamstring & 15 & $50 \%$ \\
\hline BPTB & 15 & $50 \%$ \\
\hline Total & 30 & $100 \%$ \\
\hline
\end{tabular}

Table 2: Preoperative Lysholm score

\begin{tabular}{|c|c|c|c|}
\hline Sr no. & Lysholm score & No of patients & $\%$ \\
\hline 1 & $>95$ (excellent) & 0 & 0 \\
\hline 2 & $84-94$ (Good) & 3 & $10 \%$ \\
\hline 3 & $65-83$ (Fair) & 9 & $30 \%$ \\
\hline 4 & $<65$ (poor) & 18 & $60 \%$ \\
\hline 5 & Total & 30 & $100 \%$ \\
\hline
\end{tabular}

Table 3: Post- operative Lysholm score for (ACL reconstruction using hamstring autograft)

\begin{tabular}{|c|c|c|c|}
\hline Sr no & Lysholm score & No of patients & $\%$ \\
\hline 1 & $>95$ (excellent) & 12 & $80 \%$ \\
\hline 2 & $84-94($ GooD) & 3 & $20 \%$ \\
\hline 3 & $65-83$ (Fair) & 0 & $0 \%$ \\
\hline 4 & $<65$ (Poor) & 0 & $0 \%$ \\
\hline & Total & 15 & $100 \%$ \\
\hline
\end{tabular}

Table 4: Post-operative Lysholm score using ( BPTB Autograft)

\begin{tabular}{|c|c|c|c|}
\hline Sr no & Lysholm score & No of patients & $\%$ \\
\hline 1 & $>95$ (excellent) & 11 & $73.3 \%$ \\
\hline 2 & $84-94$ (Good) & 4 & $26.6 \%$ \\
\hline 3 & $65-83$ (Fair) & 0 & $0 \%$ \\
\hline 4 & $<65$ (Poor) & 0 & $0 \%$ \\
\hline & Total & 15 & $100 \%$ \\
\hline
\end{tabular}

\section{Observations}

Age: Majority of the patients i.e 18( 60\%) were in age group of 20-29 yrs followed by age gp of 30-39 yrs and 40-49 yrs i.e 6 patients each $(20 \%)$

Sex predilection: $90 \%$ patients were male (27) and 3 were female $(10 \%)$. 


\section{International Journal of Science and Research (IJSR) \\ ISSN (Online): 2319-7064}

Index Copernicus Value (2013): 6.14 | Impact Factor (2014): 5.611

Mode of Injury: 18 cases (60\%) of ACL injury were due to road traffic accidents, while $6(20 \%)$ were due to sports injury and rest 6 cases $(20 \%)$ were due to fall.

\section{Discussion}

The ACL serves as an important stabilizing and biomechanical function for knee joint whose rupture leads to abnormal kinematics and predisposes joint to degenerative changes. ${ }^{3}$

Non-reconstructive treatment often leads to poor results. ${ }^{4}$

The main goal of reconstruction is to restore knee function without any pain and second goal is to reduce the danger of subluxation events which may le.ad meniscus injury, and increased risk of development of knee osteoarthritis.

Clancey et $\mathrm{al}^{5}$ (1982) and O' Brien et $\mathrm{al}^{6}$ (1991) reported success rates of $90 \%$ after use of open reconstruction of ACL but the post operative complications included loss of knee motion, long scar, pain in patellofemoral joint and prolonged hospital stay.

Arthroscopically assisted techniques had only minimal incision in the knee capsule and synovial membrane in the areas where the graft should be attached ${ }^{7,8}$. The two most commonly used autografts for intra-articular reconstruction of ACL are the hamstring tendon and the central third of patellar tendon. ${ }^{9}$

\section{Results}

Patients age ranged from 20 to 46 years with mean age of 31.3 years. Preoperatively majority of patients $18(60 \%)$ had poor result as per Lysholm score i.e less than 65, 9(30\%) were found to be in fair score group and 3 patients in good score. 15 patients $(50 \%)$ underwent ACL reconstruction using hamstring autograft and $15(50 \%)$ were those with patellar tendon graft. 11 patients out of 15 with patellar tendon graft had post operative excellent Lysholm score and 4 had good Lysholm score. 12 patients out of 15 using hamstring tendon had excellent Lysholm score and 3 had good Lysholm score

\section{References}

[1] Bartlett R, Catworthy M, Nguyen T. Graft selection in reconstruction of the anterior cruciate ligament. J Bone Joint Surg.2001;83:625-634

[2] Aglietti P , Buzzi R, Zaccherotti G, De Biase P. Patellar tendon versus doubled semitendinosus and gracilis tendons for anterior cruciate ligament reconstruction. Am J Sports Med.1994;22:211-217.

[3] Chaudhary D, Monga P, Joshi D, Easwaran R, Bhatia N, Singh AK, Arthroscopic reconstruction of the anterior cruciate using bone patellar tendon bone autograft: Experience of the first 100 cases. J Orthop Surg. 2005;13(2):147-152.

[4] Arbes S, Resinger C, Vecsei V, Nau T. The functional outcome of total tears of the anterior cruciate ligament in the skeletally immature patient. Intl orthop. 2007;31(4):471-475.

[5] Clancy WG Jr, Nelson DA, Reider B, Narecchania RG. Anterior cruciate Ligament reconstruction using one-third of the patellar ligament, augmented by extra-articular tendon transfers. J Bone Joint Surg. 1982;64A:352-359.

[6] O Brien sj, Warren RF, Pavlov H, Panariello R, Wickiewicz TL. Reconstruction of the chronically insufficient anterior cruciate ligament with the central third of the patellar ligament. $\mathrm{J}$ Bone Joint Surg.1991;73A:278-286.

[7] Odenset m, Gillquist J. Functional anatomy of the anterior cruciate ligament and a rationale for reconstruction. J Bone joint Surg. 1985;67A:257-262.

[8] Wilcox PG, Jackson DW. Arthroscopic anterior cruciate ligament reconstruction. Clin Sports Med. 1987:6:513524.

[9] Edgar CM, Zimmer S, Kakar S, Jones, Schepsis AA. Prospective comparison of autograft and allograft hamstring tendon constructs for ACL reconstruction. Clin orthop Relat Res. 2008:466(9)2238-2246.

\section{Author Profile}

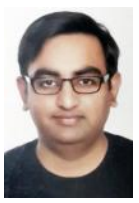

Dr. Sahil Saini did his M.B.B.S from Govt Medical College Kangra, H.P. and now pursuing his M.S in orthopaedics from M.M.I.M.S.R , Mullana Ambala as $2^{\text {nd }}$ year junior resident.

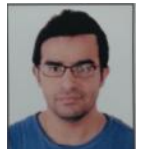

Dr Manu Soni did his M.B.B.S from M.D.U Rohtak, Haryana and now pursuing his M.S in orthopaedics from M.M.I.M.S.R , Mullana Ambala as 3rd year junior resident. 